\title{
Enhancing learning outcomes through new e-textbooks: A desirable combination of presentation methods and concept maps
}

\author{
Kuo-Liang Huang \\ National Cheng Kung University, Taiwan \\ Kuo-Hsiang Chen \\ I-Shou University, Taiwan \\ Chun-Heng Ho \\ National Cheng Kung University, Taiwan
}

\begin{abstract}
It is possible that e-textbook readers and tablet PC's will become mainstream reading devices in the future. However, knowledge about instructional design in this field of learning sciences is inadequate. This study aimed to analyse how two factors, that is, presentation methods and concept maps, interact with cognitive load and learning outcomes when the contents of e-textbooks are compiled. Further, it endeavored to suggest an adequate logic of instructional design based on the findings. An empirical method was adopted, and 78 participants - either undergraduates or graduates in college - were recruited. Regarding the compilation of e-textbooks, the findings can be summarised as follows: (a) Providing concept maps not only reduces learners' cognitive load but also enhances their learning outcomes of cognition, affection, and psychomotor performance. (b) Overall, video (V) is superior to text and diagram interaction (TDI) in terms of learning outcomes, and TDI is superior to text and diagram (T\&D). Nevertheless, within the cognitive domain, learning outcomes produced by $\mathrm{V}$ are not necessarily superior to those produced by TDI. When learners are not provided with concept maps, TDI is superior to $\mathrm{V}$ in terms of learning outcomes. Conversely, if learners are provided with concept maps, $\mathrm{V}$ is superior to TDI.
\end{abstract}

\section{Introduction}

Recently, tablet PCs have been applied to educational activities. By integrating software and hardware well, tablet PCs provide novel and attractive applications (Shah, 2012; Young, 2012). Yet, standard formats of e-book applications (i.e., ePub and PDF) had not taken full advantage of the capabilities of tablet PCs. To solve this problem, Apple Inc. reinvented e-textbooks by releasing an e-book platform, iBooks 2, together with an e-book format, iBook, in early 2012. The most noteworthy characteristics of iBooks 2 are an appealing layout and interactive multimedia contents much more diverse than before. In addition to static pictures and videos, iBooks 2 and the iBook format enable users to conduct virtual, tactile, and interactive learning, namely, to experience interactive images and 3D objects on the multi-touch screen with their fingers, as shown in Figure 1.

The field of learning sciences draws the perspectives of psychology and education to understand how people learn.,Special attention is paid to how learning materials should be treated to reduce learners' cognitive load (Mayer, 2008). Cognitive load, or the load of working memory (WM), refers to the load imposed on a learner's cognitive system as a specific message is being processed (van Merriënboer \& Sweller, 2010). Previous studies suggest that learning outcomes are influenced not only by learners' characteristics and interactions with learning environments but also by the treatment of learning materials (Hede, 2002; Smith \& Woody, 2000). Therefore, if instructional design is employed to treat learning materials of e-textbooks appropriately, learners will be assisted with reducing cognitive load and enhancing learning outcomes in their learning process (Lai \& Newby, 2012; Sweller \& Chandler, 1994). 

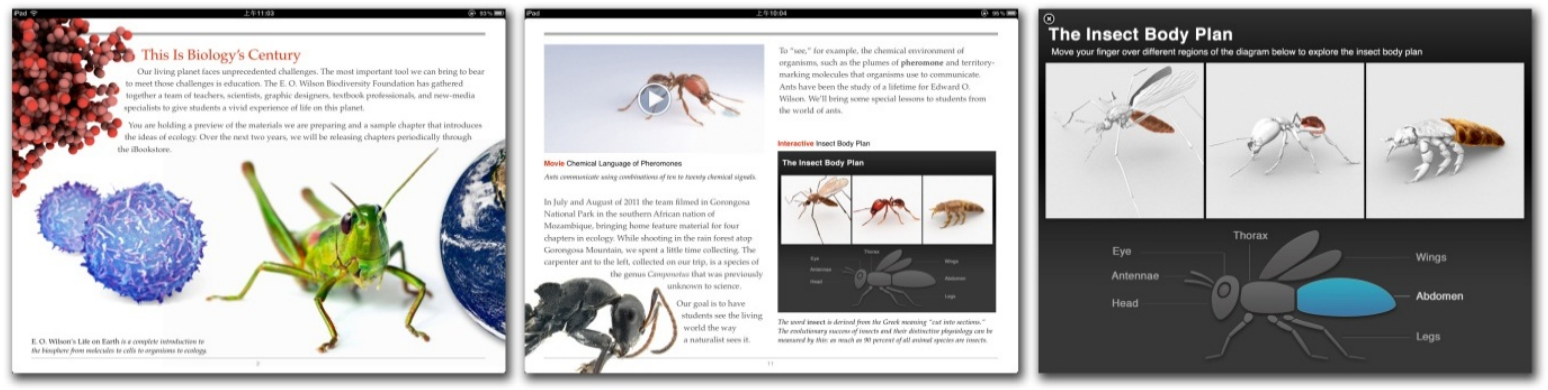

Figure 1. Application of e-textbooks through iBooks2 and the .ibook format (adapted from Wilson, Ryan, \& McGill, 2012).

Multimedia learning materials which are perceived by both visual and audio organs (i.e., the dual-sensed method) produce a much better effect on learning outcomes than the single-sensed method (Kalyuga, 2000; van Merriënboer \& Sweller, 2010). Realising that a person's WM capacity is limited, some scholars have introduced the cognitive load theory into instructional design. More importantly, their chief aim is to discover a desirable presentation method that combines multiple kinds of media, conveys specific information effectively to learners, and improves learning outcomes (Sweller, 1990; Sweller \& Chandler, 1994).

As for the organisation and layout of an e-textbook, it is presented mainly through texts and pictures, involving less interaction and multimedia application; furthermore, its structure primarily includes contents, articles, and exercises. Previous studies indicate that after recognising and conceptualising a knowledge framework, learners comprehend the knowledge contents of learning materials more deeply, thereby acquiring better learning outcomes (Jonassen, 1997). By means of a diagram, a reading concept map presents the relationship between concepts in a hierarchical knowledge framework (Hwang, Wu, \& Ke, 2011). Also, the concept map is thought to help learners to construct a schema, to acquire the knowledge framework of learning contents, and to connect new information to prior experiences (Hathorn \& Rawson, 2012; Novak \& Gowin, 1984), with learning outcomes upgraded (Chang, Sung, \& Chiou, 2002). Consequently, the concept map is frequently used as an auxiliary learning tool in instructional design.

Concerning the instructional design of e-textbooks, the primary challenges involving presentation methods of learning materials and the use of concept maps are to facilitate cognitive processing, reduce learners' cognitive load in the learning or cognitive process, as well as enhance learning outcomes (Mayer, 2008). Based on the novel and attractive e-textbook readers, the presentation methods of learning materials, including the layout of concept maps, constitutes a crucial and interesting topic of research. Given this, this study focused on the following issues: (a) how the interactions between various presentation methods of learning materials and concept maps affects cognitive load; (b) how the interactions between various presentation methods of learning materials and concept maps affects the learning outcomes of cognition, affection, and psychomotor performance; and (c) how cognitive load affects learning outcomes. In addition, the logic of compilation which could be used as a practical reference was identified.

\section{Theoretical background}

\section{Cognitive theory of multimedia learning}

Multimedia learning is a learning method which integrates words, including texts and narrations, with pictures, including diagrams, charts, pictures, maps, animations, and videos (Mayer, 2001, 2011). According to previous studies, as individuals actively use multimedia learning, their cognitive processing involves the following steps. First, they select relevant information of objects that catch their attention, incorporating this information into their Working Memory (WM). Subsequently, they organise the selected pieces of information, establishing the relationships between discrete pieces of information. Finally, they extract 
relevant knowledge from their long-term memory (LTM), integrating such knowledge (Mayer, 2008; Mayer, Heiser, \& Lonn, 2001).

After integrating the relevant perspectives of cognitive learning, Mayer (2005) presented a "cognitive theory of multimedia learning, p31." In accordance with the theory, when multimedia learning is conducted, various presentation methods require different cognitive processing procedures, as shown in Figure 2.

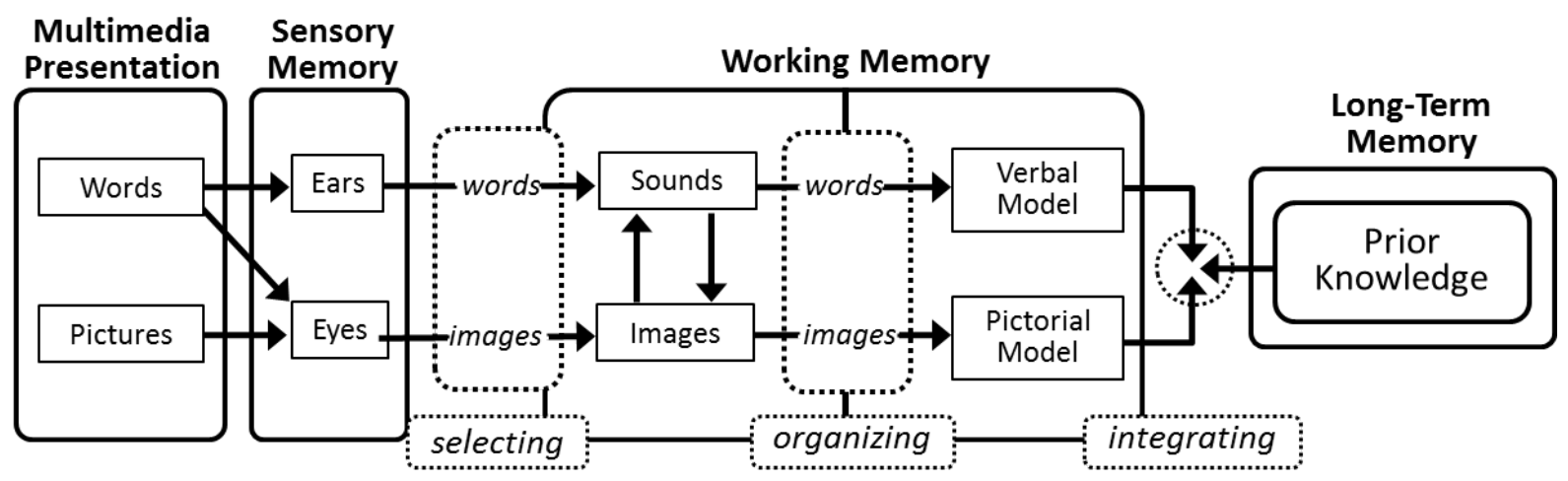

Figure 2. Cognitive theory of multimedia learning (adapted from Mayer, 2005, Figure 3.2, p. 37).

Pictures, including charts and animations, are perceived by the eyes and selected by WM before being incorporated into the image channel. After being organised, pictures are transformed into pictorial models and integrated with prior knowledge. Narrations are sensed by the ears and selected by WM before being incorporated into the sound channel. After being organised, narrations are transformed into verbal models and integrated with prior knowledge. Texts are perceived by the eyes and selected by WM before being incorporated into the image channel. They are then transferred to the sound channel. After being organised, texts are transformed into verbal models and integrated with prior knowledge.

As indicated by the above, the sensory capacity and duration of visual and audio channels are limited. Consequently, the key to successful learning outcomes depends on whether multimedia presentations are properly used so that critical information may enter WM efficiently and undergo relevant cognitive processing.

\section{Working memory load imposed on learners' cognitive systems}

Recently, a lot of scholars have applied the cognitive load theory to instructional design in order to identify presentation methods that effectively communicate information to learners, thereby enhancing learning outcomes (Pastore, 2012). Starting from the standpoint of learning, psychologists Sweller, van Merriënboer, and Paas (1998) presented the cognitive architecture. Furthermore, because of a limited WM capacity (Lin \& Atkinson, 2011), the interference coming from cognitive load should be minimised when learners operate their WM (Ruiz, Cook, \& Levinson, 2009). Thus, new knowledge can be incorporated into the relevant knowledge schema and then stored in LTM, which has an unlimited capacity (Issa et al., 2011).

Regarding the measurement of cognitive load, Wierwille and Eggemeier (1993) presented three techniques; namely, subjective technique, physiological technique, and task and performance-based technique. Under the subjective technique, a scale is used to measure the cognitive load perceived by the participant. Under the physiological technique, certain instruments are employed to measure the physiological changes in the participant's heartbeats, brain activities, etc. Under the task and performance-based technique, the size of a participant's cognitive load is inferred by measuring the relationship between the performance and the complexity of a task. 
Cognitive load occurs during the WM phase while learning outcomes depend on LTM. Therefore, learning outcomes can be enhanced by reducing the cognitive load assumed by WM so that LTM may integrate knowledge smoothly.

\section{Concept map}

Defined by the scholars Novak and Gowin (1984), the concept map uses a diagram to represent the hierarchical structure of knowledge (Berlanga, van Rosmalen, Boshuizen, \& Sloep, 2012; Elorriaga et al., 2011). The schematic diagram corresponds to the concepts, propositions, cross-links, and hierarchical relationships of a knowledge framework, so individual concepts as well as their relationships within a specific topic are visualised and presented holistically (Elorriaga et al., 2011; Koc, 2012). In this way, learners are enabled to organise their knowledge and learning experiences, in addition to integrating learning materials (Hwang et al., 2011). Judging from their forms, concept maps exhibit the symbolic characteristics of both words and pictures (Novak \& Gowin, 1984).

As for teaching applications, concept maps are divided into concept maps and concept mapping. Like advance organisers, concept maps are provided for learners as learning scaffolds (Elorriaga et al., 2011; Koc, 2012). Concept maps guide learners to select, organise, and integrate new information during cognitive processing. By contrast, concept mapping can be used to evaluate learning outcomes after instruction (Kao, Lin, \& Sun, 2008). According to the cognitive theory of multimedia learning, concept maps which represent words and pictures can help learners enhance their learning outcomes through cognitive processing.

\section{Technology-mediated learning and learning outcomes}

Academically, technology-enhanced learning (TEL) refers to all the learning methods that use information and communication technologies (ICT) as a medium. In compliance with such a concept, Alavi and Leidner (2001) presented a conceptual framework of technology-mediated learning (TML), as shown in Figure 3. They suggested that ICT and instructional strategy produce different influences on learners' psychological learning processes, thus determining learning outcomes in specific learning contexts. TML emphasises that learners' psychological learning processes should be used as a mediator to understand their learning outcomes.

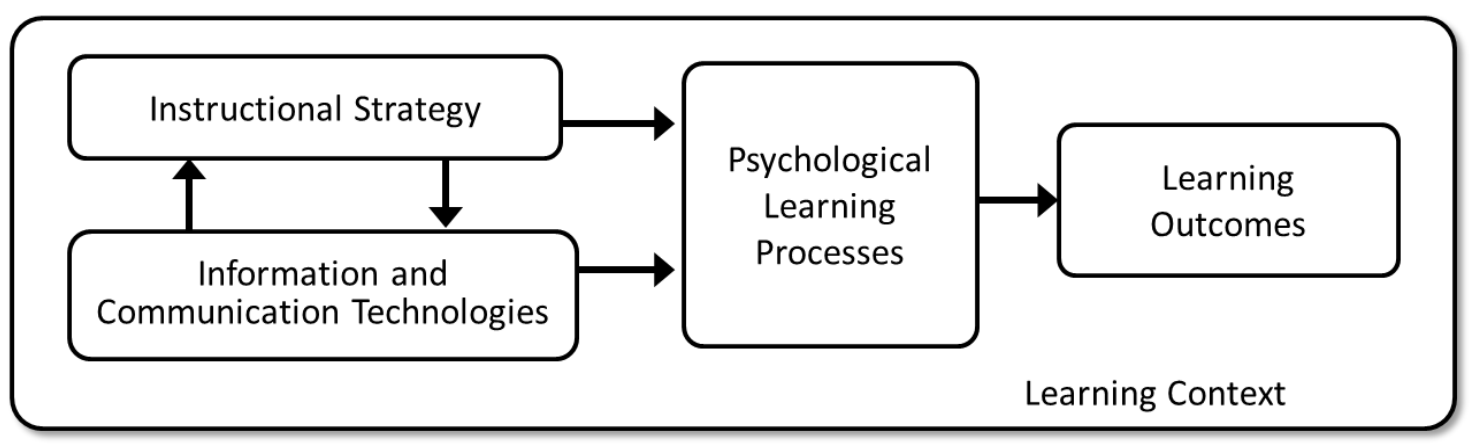

Figure 3. The conceptual research framework of TML (adapted from Alavi \& Leidner, 2001).

From the foregoing perspective, it is clear that research on learning outcomes in the TEL-based mode should focus on how ICT and instructional strategy interact with learners' inner psychological learning processes. Meanwhile, the relationship that generates better learning outcomes should be discovered.

\section{Evaluating learning outcomes}

Learning induces persistent changes in a person's knowledge, behaviours and values; consequently, it produces various learning outcomes. Based on different contents and characteristics of knowledge, Bloom (1984) divided learning outcomes into three categories; namely, the cognitive domain (CD), affective domain 
(AD), and psychomotor domain (PD). To be exact, $\mathrm{CD}$ is the result of memorising, contemplating, differentiating, and applying knowledge (Simpson, 1972). AD refers to a person's inner feeling, attitude, interest, and level of acceptance or rejection concerning a certain topic (Kearney, 2004; Linn \& Miller, 2005), all of which are internalised to form a person's inner values (Lee, 2009). Being the combination of psycho and motor, PD is the specific, observable, and external actions or behaviours guided by psychology (Simpson, 1972). Such a classification of learning outcomes has been widely applied (Anderson, Krathwohl, Airasian, Cruikshank, \& Mayer, 2001) and used as an indicator (Bobrowski, n.d.; Sharda et al., 2004).

\section{Method}

\section{Research model and correlated variables}

Considering the findings and questions of related literature, the authors present a research model, as shown in Figure 4, based on the conceptual framework of TML proposed by Alavi and Leidner (2001).

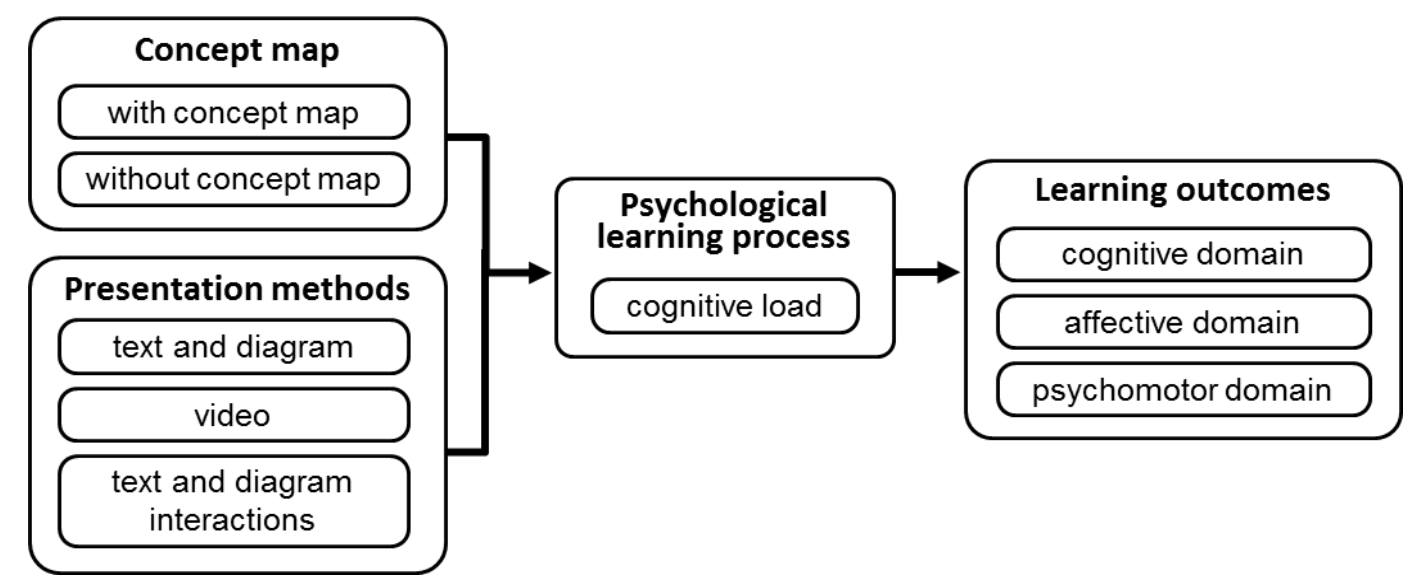

Figure 4. The research model of this study.

\section{Instructional strategy}

Concept maps and presentation methods of e-textbooks were taken as two manipulated variables. Depending on whether a concept map was available, the e-textbook layout was designed in two ways; namely, with a concept map (Y) and without a concept map (N). In accordance with that design, we investigated how concept maps influenced learners' cognitive loads and learning outcomes. Furthermore, based on Apple's diverse, interactive presentation methods for e-textbooks, there were three ways in which we did this: that is, text and diagram (T\&D), video (V), and text and diagram interaction (TDI), as shown in Table 1. As a presentation method for content, T\&D is similar to past textbooks, but it was presented in the form of texts and diagrams. As for $\mathrm{V}$, which is the use of films, but relies mainly on diagrams together with narrations. Based on texts and diagrams, TDI incorporates the multi-touch screen, applying technologies such as interactive images and 3D objects to its diagrams. Thus, the knowledge contents originally belonging to textual presentation are integrated, with much more information, which can be easily cognitively processed. Meanwhile, learners select by clicking on the contents that interest them, thereby acquiring more experiences with interactive learning. 
Table 1

Differences among the three presentation methods

\begin{tabular}{llc}
\hline Presentation methods & Design orientation of materials & Sensory modalities \\
\hline Text and diagram (T\&D) & Mainly texts and diagrams & Visual \\
Video (V) & Narrations that integrate texts and diagrams & Audiovisual \\
Text and diagram & Integrating texts and diagrams through interactive & Visual \\
interaction (TDI) & images and 3D objects & \\
\hline
\end{tabular}

Information and communication technologies

In compliance with the scope of this study, the authors adopted Apple iPad, the reading platform iBooks 2.1, and the e-books in the iBook format as research materials; but they were not manipulated.

Psychological learning processes

The cognitive load imposed on the cognitive system while learners were processing specific messages was taken as a mediator.

Learning outcomes

The evaluation indicator of learning outcomes addressed three constructs; namely, CD, AD, and PD.

\section{Experimental design and validity}

The following factors were controlled to prevent potentially confounding variables from influencing the causal relationships:

- Random assignment and between-subjects factorial designs were adopted during the experimental design to minimise such problems as selection bias.

- To ensure consistent prior experiences of the participants, a checklist was employed to pick out those candidates who had had no specific learning experience with the topic, that is, myocardial infarction, before they were recruited.

- An analysis of covariance (ANCOVA) was carried out to control the effects of the pre-test scores (regarded as covariates) on the post-test scores.

- A laboratory experiment was conducted to control the experimental context properly; moreover, to minimise the error variance caused by some extra factors, the same instructional language was used throughout the experiment.

Furthermore, the following recruitment criteria were established to ensure that the participants possessed consistent educational levels and capabilities: (a) having no specific learning experience with myocardial infarction; (b) students enrolled in undergraduate and graduate programs, regardless of gender; (c) knowing how to operate iPad and iBooks and having at least 1 month of user experience; and (d) having no significant visual or hearing impairment after correction.

\section{Learning materials}

In this study, the knowledge topic of the e-textbook reading material was selected based on the following considerations:

- Its content was suitable for participants who generally had lower entry competencies.

- The learning domains of cognition, affection, and psychomotor performance had to be covered uniformly. 
- After learning, the participants would find the course practical. After careful evaluation, the pathology, first aid, and treatment concerning myocardial infarction were chosen as the learning material.

The design process involved is described as follows:

1. In addition to the purpose of the learning material, the participants' characteristics and entry competencies were defined.

2. Two qualified emergency physicians and one professor in the nursing department of a university were invited to form a subject matter expert (SME) group. Based on process 1 above, this SME group jointly established the learning objectives, learning material, concept mapping, and a draft of the examination questions.

3. A professional e-instructional designer performed the subsequent instructional design.

4. The learning material was produced by a multimedia designer using the production software iBooks Author. The structure of the e-textbook included the following in sequence: the front cover, table of contents, glossary, preface, course objectives, concept map, unit objectives, unit contents, and section contents, as shown in Figure 5. The learning material was divided into three chapters, that is: Chapter 1: Introduction to myocardial infarction; Chapter 2: Diagnosis and pathology; and Chapter 3: First aid and treatment. There were 7863 words in the T\&D version of the material without a concept map.
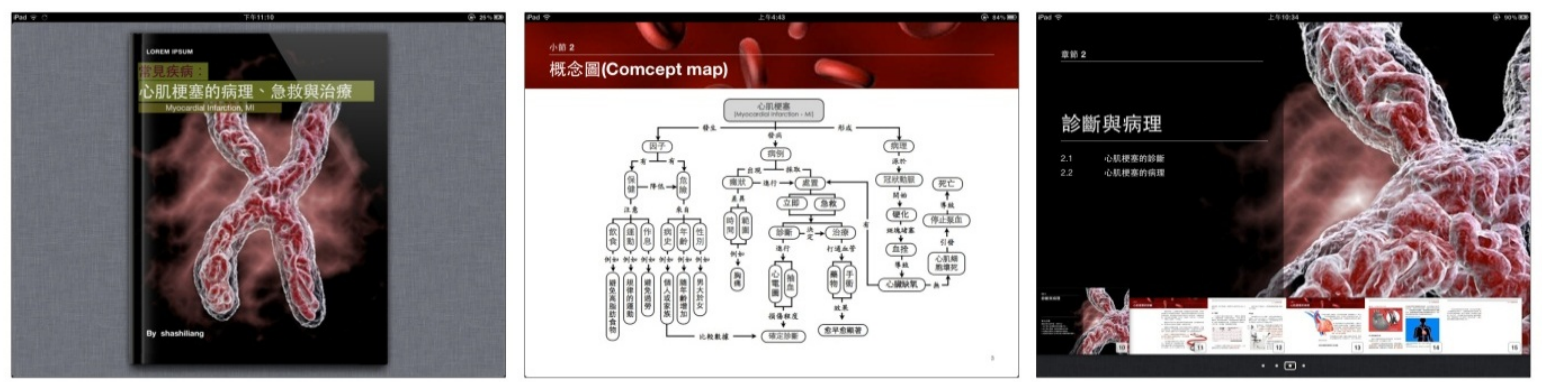

Figure 5. The e-textbook designed in this study serving as the learning material during the experiment. From left to right, (a) the front cover of the e-textbook (b) the concept map page (c) the chapter, sections, pages, and structure

Besides, to ensure consistency among the six versions of e-textbook design, the layout of each version was identical, except for variables such as the presentation method for experimental manipulation and the availability of a concept map. For example, regarding the formation of myocardial infarction, the design orientations of e-textbooks included the following: T\&D integrating texts and diagrams, $\mathrm{V}$ using narrations to integrate diagrams, and TDI integrating T\&D through interactive images and 3D objects, as shown in Figure 6.
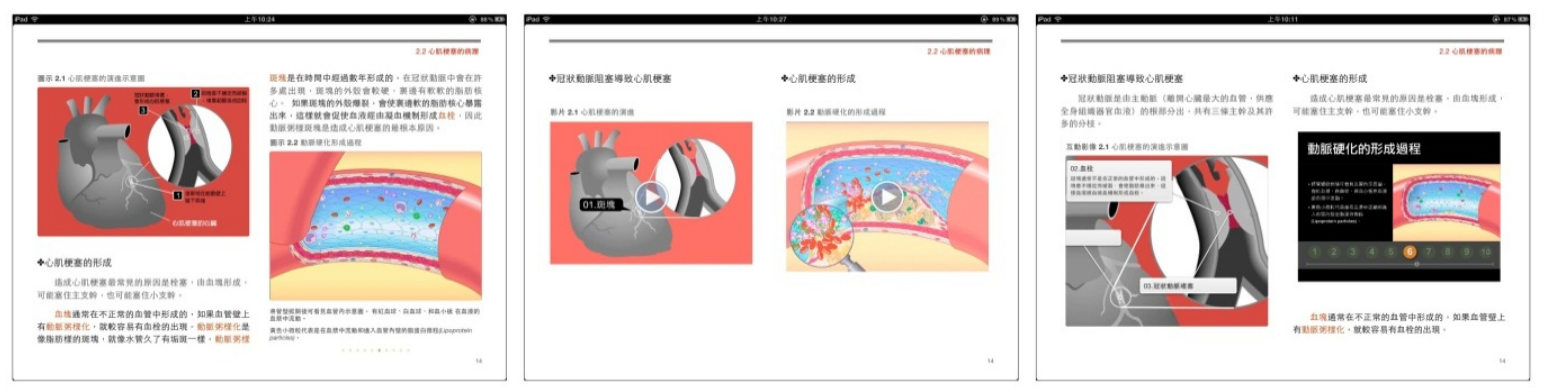

Figure 6. Different presentation methods showing different versions.

From left to right, (a) text and diagram (b) video (c) text and diagram interaction 


\section{Definitions and measurements of study variables}

Based on the scope and objectives of this study, the research constructs and operational definitions were established, as shown in Table 2. As indicated by previous studies on the measurement of cognitive load (Sweller et al., 1998; Paas \& van Merriënboer, 1994), the subjective technique is more sensitive, reliable, valid, and interference-free when used to measure the relatively small difference in cognitive load. By contrast, though also free from interference, the physiological technique is less reliable and valid; moreover, it is sensitive only to the relatively big difference in cognitive load. In consideration of the above, this study adopted the subjective technique; further, the cognitive load scale developed by other researchers was used (Cerpa, Chandler, \& Sweller, 1996; Kalyuga, 2000), which contained 5 questions. This was a 7-point Likert scale, ranging from 7 (strongly disagree) to 1 (strongly agree), and the sum of the scores represented a participant's cognitive load.

Table 2

Operational definitions and measurement of study variables

\begin{tabular}{lll}
\hline \multicolumn{1}{c}{ Construct } & \multicolumn{1}{c}{ Operational definition } & \multicolumn{1}{c}{ Source of the measurement } \\
\hline Cognitive load & $\begin{array}{l}\text { Through the self-report method, the } \\
\text { level of cognitive load was measured } \\
\text { with a cognitive load scale. }\end{array}$ & $\begin{array}{l}\text { The scales proposed by } \\
\text { Cerpa et al. (1996); } \\
\text { Kalyuga (2000) }\end{array}$ \\
Cognitive domain (CD) & $\begin{array}{l}\text { The CD test was held to obtain the } \\
\text { respondents' scores. }\end{array}$ & $\begin{array}{l}\text { Composed by the SME } \\
\text { Affective domain (AD) }\end{array}$ \\
$\begin{array}{l}\text { Through the self-report method, the } \\
\text { inner value and attitude resulting from } \\
\text { the learning process were measured } \\
\text { with an AD scale. }\end{array}$ & $\begin{array}{l}\text { The scale proposed by } \\
\text { Lee (2009) }\end{array}$ \\
Psychomotor domain (PD) & $\begin{array}{l}\text { On-site observation and a performance } \\
\text { checklist were used to evaluate } \\
\text { psychomotor domain. }\end{array}$ & Composed by the SME \\
\hline
\end{tabular}

Composing the $\mathrm{CD}, \mathrm{AD}$, and $\mathrm{PD}$ test papers: First, based on the research design, the authors rewrote the examination questions drafted by the SME group, referencing the principles of examination questions proposed by Gronlund (1993) and Mehrens and Lehmann (1991). Then, the rewritten questions were validated by the SME group. Finally, a pre-test was conducted using the finalised draft to ensure the effectiveness of the experimental procedure and evaluation tools as well as the appropriateness of the questions.

CD test: This was meant to measure memorisation and comprehension of knowledge. Its question format and scoring method were as follows. The five fill-in-the-blank questions contained 15 blanks, with 5 points for each blank. Each participant was given a basic score of 25 points. Thus, the total score was 100 points. The higher the score, the higher a participant's cognitive level.

AD test: This was intended to measure the participant's inner value and attitude towards myocardial infarction. Currently, there are three commonly used measurement methods for the affective domain (AD): self-report, teacher observation, and peer evaluation. Among the three methods, none have been generally considered to be the best (Lee, 2009). In this study, the AD test put more stress on an individual's inner value and attitude, so the most direct method, namely, the self-report method, was adopted. As subjective evaluation of CPR-related matters was conducted, the test items included the value of cardiopulmonary resuscitation (CPR), behavioural intention before CPR, and responsibility awareness of CPR. The authors referenced the scale developed by Lee (2009) to compose the questions in the test paper. Specifically, 10 items were 
measured on a 7-point Likert scale. The participants' attitudes and behavioral intentions were rated from 1 (strongly disagree) to 7 (strongly agree).

PD test: Following the established scenario clues, the participants performed CPR on the first aid training manikins. Then, a performance checklist provided by the SMEs was used to test the participants. Owing to a comparatively brief period of learning time, the test focused on accuracy and effectiveness of CPR procedures rather than a smooth and skillful performance. The test questions contained 20 items. Moreover, 4 points were given for each correct and effective movement, and each participant had a basic score of 20 points, with the total being 100 points.

\section{Instruments and procedure}

The instruments and materials used in the experiment consisted of a random number table, e-textbooks of various versions, an iPad, and a first aid training manikin. The entire experiment was composed of six steps, as listed in Table 3.

Table 3

Detailed instructions and experimental procedures

\section{Procedure}

\section{Duration}

1. Pre-test

1-1 The $\mathrm{CD}$ and $\mathrm{AD}$ tests were conducted.

$10 \min$

1-2 The PD performance test was conducted under situational prompts.

$5 \min$

\section{Random assignment}

Based on a random table number, the participants were randomly assigned to a group using a block randomisation method.

\section{Contextual setting}

The temperature and light settings in the laboratory were adjusted to ensure that the participants were comfortable.

4. Instructions on the experiments

Experimental activities and agenda were explained through PowerPoint slides.

$3 \min$

5. Experimental manipulations

Learning materials were provided for the participants according to the group they were in and were read on the iPad.

$30 \min$

6. Surveying and testing

6-1 The CD scale was completed.

$2 \min$

6-2 The $\mathrm{CD}$ and $\mathrm{AD}$ tests were conducted.

$10 \min$

6-3 The PD performance test was administered on the first aid training manikin under situational prompts.

$5 \min$

\section{Results}

\section{Demographics}

Seventy-eight participants were randomly assigned to the $2 \times 3$ design model for the presentation methods (three treatments) and concept maps (two treatments), with each group containing 13 participants. Table 4 lists the age and gender distributions of the participants in each group. The participants consisted of 51 
undergraduates and 27 graduates. Of them, 24 majored in education, 20 in engineering, 18 in design, 11 in business, and 4 in other sciences.

Table 4

The gender and age distributions of the participants in each group

\begin{tabular}{lccccc}
\hline \multirow{2}{*}{ Experimental group } & \multicolumn{3}{c}{ Gender } & \multicolumn{3}{c}{ Age } & \\
\cline { 2 - 5 } & Male & Female & $M$ & $S D$ & $n$ \\
\hline Y- T\&D & 7 & 6 & 22.77 & 2.28 & 13 \\
Y -V & 5 & 8 & 23.46 & 2.40 & 13 \\
Y-TDI & 6 & 7 & 22.85 & 2.30 & 13 \\
N-T\&D & 8 & 5 & 23.00 & 1.87 & 13 \\
N-V & 7 & 7 & 24.77 & 2.49 & 13 \\
N-TDI & 4 & 9 & 23.23 & 2.01 & 13 \\
\hline
\end{tabular}

Note. $\mathrm{Y}=$ with a concept map; $\mathrm{N}=$ without a concept map; $\mathrm{T} \& \mathrm{D}=$ text and diagram; $\mathrm{V}=$ video; $\mathrm{TDI}=$ text and diagram interaction.

\section{Means and standard deviations of study variables for each experimental group}

Table 5 lists the means and standard deviations obtained by each experimental group, with the two manipulated factors (i.e., presentation methods and concept maps) corresponding to the study variables.

Table 5

Means and standard deviations of study variables

\begin{tabular}{|c|c|c|c|c|c|c|}
\hline \multirow[b]{3}{*}{ Variables } & \multicolumn{6}{|c|}{ Experimental group ${ }^{a}$} \\
\hline & \multicolumn{3}{|c|}{ With concept maps } & \multicolumn{3}{|c|}{ Without concept maps } \\
\hline & $\mathrm{T} \& \mathrm{D}$ & $\mathrm{V}$ & TDI & $T \& D$ & $\mathrm{~V}$ & TDI \\
\hline Cognitive load & $\begin{array}{l}21.62 \\
(3.28)\end{array}$ & $\begin{array}{l}11.23 \\
(2.98)\end{array}$ & $\begin{array}{l}14.85 \\
(3.13)\end{array}$ & $\begin{array}{l}27.23 \\
(2.49)\end{array}$ & $\begin{array}{l}13.46 \\
(2.79)\end{array}$ & $\begin{array}{l}15.77 \\
(3.79)\end{array}$ \\
\hline $\begin{array}{l}\text { Cognitive domain } \\
\text { pre-test }\end{array}$ & $\begin{array}{l}42.69 \\
(8.07)\end{array}$ & $\begin{array}{l}41.54 \\
(4.27)\end{array}$ & $\begin{array}{c}43.08 \\
(11.46)\end{array}$ & $\begin{array}{l}40.15 \\
(4.6)\end{array}$ & $\begin{array}{l}40.77 \\
(7.87)\end{array}$ & $\begin{array}{l}38.85 \\
(5.06)\end{array}$ \\
\hline $\begin{array}{l}\text { Cognitive domain } \\
\text { post-test }\end{array}$ & $\begin{array}{l}73.85 \\
(4.16)\end{array}$ & $\begin{array}{l}86.54 \\
(4.72)\end{array}$ & $\begin{array}{l}84.62 \\
(3.80)\end{array}$ & $\begin{array}{l}70.15 \\
(3.58)\end{array}$ & $\begin{array}{l}76.85 \\
(4.63)\end{array}$ & $\begin{array}{l}80 \\
(5)\end{array}$ \\
\hline Affective & 74.15 & 73.54 & 72.31 & 73.23 & 71.69 & 69.23 \\
\hline domain pre-test & (3.11) & $(3.84)$ & $(4.75)$ & $(4.44)$ & $(5.02)$ & (6.19) \\
\hline $\begin{array}{l}\text { Affective domain } \\
\text { post-test }\end{array}$ & $\begin{array}{l}83.54 \\
(4.68)\end{array}$ & $\begin{array}{l}87.77 \\
(4.17)\end{array}$ & $\begin{array}{l}83.38 \\
(2.60)\end{array}$ & $\begin{array}{l}80.69 \\
(2.93)\end{array}$ & $\begin{array}{l}84.54 \\
(3.46)\end{array}$ & $\begin{array}{l}82.23 \\
(3.29)\end{array}$ \\
\hline $\begin{array}{l}\text { Psychomotor } \\
\text { domain pre-test }\end{array}$ & $\begin{array}{l}46.46 \\
(6.64)\end{array}$ & $\begin{array}{c}46.77 \\
(11.36)\end{array}$ & $\begin{array}{l}47.08 \\
(9.82)\end{array}$ & $\begin{array}{l}45.38 \\
(6.85)\end{array}$ & $\begin{array}{l}45.08 \\
(7.73)\end{array}$ & $\begin{array}{l}41.85 \\
(5.57)\end{array}$ \\
\hline $\begin{array}{l}\text { Psychomotor domain } \\
\text { post-test }\end{array}$ & $\begin{array}{l}76.31 \\
(5.77)\end{array}$ & $\begin{array}{l}86.77 \\
(3.42)\end{array}$ & $\begin{array}{l}83.85 \\
(4.14)\end{array}$ & $\begin{array}{l}73.54 \\
(4.48)\end{array}$ & $\begin{array}{l}84.15 \\
(4.85)\end{array}$ & $\begin{array}{c}81 \\
(3.58)\end{array}$ \\
\hline
\end{tabular}

Note. $\mathrm{T} \& \mathrm{D}=$ text and diagram; $\mathrm{V}=$ video; $\mathrm{TDI}=$ text and diagram interaction.

${ }^{\mathrm{a}}$ The numbers in the brackets are the standard deviations.

\section{Effects of presentation methods and concept maps on cognitive load}

A two-way ANOVA was performed to verify the effects of various presentation methods and concept maps on cognitive load, with presentation methods and concept maps treated as independent variables (IVs) and cognitive load treated as the dependent variable (DV). 
The homogeneity of variances was confirmed through Levene's test of equality of error variances. The results indicated that $P=.4>.05$, suggesting that the variables among the experimental groups were homogeneous and that ANOVA could be conducted. Regarding the effect analysis of the participants, the interaction between the two factors was found to achieve a level of significance $(F=3.96, P=.023<.05)$, indicating that the two factors interacted. Hence, a simple main effects test was conducted, with the results summarised in Table 6.

Table 6

The results of ANOVA concerning the simple main effects of various presentation methods and concept maps on cognitive load

\begin{tabular}{lrrrrr}
\hline Source & \multicolumn{1}{c}{ SS } & df & \multicolumn{1}{c}{ MS } & F & Posteriori comparisons \\
\hline Concept maps & & & & & \\
\hline T\&D & 204.962 & 1 & 204.962 & $24.19^{* * *}$ & $\mathrm{Y}<\mathrm{N}$ \\
V & 32.346 & 1 & 32.346 & $3.89 *$ & $\mathrm{Y}<\mathrm{N}$ \\
TDI & 5.538 & 1 & 5.538 & $.46 \mathrm{~ns}$ & \\
\hline Presentation methods & & & & & $\mathrm{V}<\mathrm{TDI}<\mathrm{T} \& \mathrm{D}$ \\
Y & 722.513 & 2 & 361.256 & $36.834^{* * *}$ & $\mathrm{~V}<\mathrm{T} \& \mathrm{D} ; \mathrm{TDI}<\mathrm{T} \& \mathrm{D}$ \\
\hline N & 1413.897 & 2 & 706.949 & $74.887 * * *$ & $\mathrm{~V}$
\end{tabular}

Note. $\mathrm{Y}=$ with a concept map; $\mathrm{N}=$ without a concept map; $\mathrm{T} \& \mathrm{D}=$ text and diagram; $\mathrm{V}=$ video; $\mathrm{TDI}=$ text and diagram interaction.

$* * * P<.001, * P<.05$, n.s. $P>.05$

As for the factor effects of concept maps, having or not having a concept map significantly affected the participants' cognitive load in the T\&D $(F=24.19, P<.001)$ and $\mathrm{V}(F=3.89, P=.043)$ groups. After posteriori comparisons, it was discovered that, in the T\&D group, the cognitive load of the participants with $Y$ $(M=21.62)$ was less than those with $\mathrm{N}(M=27.23)$. In the $\mathrm{V}$ group, the cognitive load of the participants with Y $(M=14.85)$ was less than those with $\mathrm{N}(M=15.77)$. However, as no concept map was provided for the participants in the TDI group $(F=0.46, P=.505)$, there was no significant difference in the cognitive load.

Regarding the factor effects of presentation methods, $\mathrm{Y}$ and $\mathrm{N}$ had significant effects on the cognitive load of the participants employing various presentation methods $(F=36.83, P<.001 ; F=74.89, P<.001$, for $\mathrm{Y}$ and $\mathrm{N}$ respectively). Posteriori comparisons show that, when a concept map was provided (Y), the cognitive load of the participants in the $\mathrm{V}$ group $(M=11.23)$ was significantly $(p<.021)$ less than that of the participants in the TDI group $(M=14.85)$. Moreover, the cognitive load of the participants in the TDI group $(M=14.85)$ was significantly $(P<.001)$ less than that of the participants in the T\&D group $(M=21.62)$. When a concept map was not provided $(\mathrm{N})$, the cognitive load of the participants in the $\mathrm{V}$ group $(M=13.46)$ was significantly $(p<.001)$ less than that of the participants in the T\&D group $(M=27.23)$. Likewise, the cognitive load of the participants in the TDI group $(M=15.77)$ was significantly $(p<.001)$ less than that of the participants in the T\&D group $(M=27.23)$. However, the cognitive load of the participants in the $\mathrm{V}$ group $(M=13.46)$ was not significantly $(p=.174)$ less than that of the participants in the TDI group $(M=15.77)$.

\section{Effects of presentation methods and concept maps on the learning outcomes of cognition, affection, and psychomotor performance}

An ANCOVA was conducted to analyse the effects of various presentation methods and concept maps on the learning outcomes of cognition, affection, and psychomotor performance. Therein, the presentation methods and concept maps were treated as independent variables, the pre-test scores of cognition, affection, and psychomotor performance were treated as control variables, and the post-test scores of cognition, affection, and psychomotor performance were treated as dependent variables. 
Effects of presentation methods and concept maps on the learning outcomes of cognition After a within-group regression coefficient homogeneity test was carried out, neither the cognitive domain post-test $\times$ presentation methods $(F=1.02, P=.37)$ nor the cognitive domain post-test $\times$ concept maps $(F=$ $.01, P=.93)$ reached a level of significance $(P>.05)$. In such a case, an ANCOVA could be directly conducted. Besides, the homogeneity of variances was examined through Levene's test of equality of error variances, with the results indicating that the variances of the various groups were homogeneous $(P=.232>$ $.05)$ and that an ANCOVA could be conducted. After the effect of the cognitive domain pre-test was eliminated, the two factors showed significant interactions $(F=9.78, P<.001)$ in the cognitive domain post-test. Therefore, a test of simple main effects was performed, with the results summarised in Table 7 .

Table 7

The results of ANCOVA concerning the simple main effects of various presentation methods and concept maps on the cognitive domain

\begin{tabular}{|c|c|c|c|c|c|}
\hline Source & SS & df & MS & $\mathrm{F}$ & Posteriori comparisons \\
\hline \multicolumn{6}{|l|}{ Concept maps } \\
\hline $\mathrm{T} \& \mathrm{D}$ & 47.58 & 1 & 47.58 & $4.94 *$ & $\mathrm{Y}>\mathrm{N}$ \\
\hline V & 557.02 & 1 & 557.02 & $52.75^{* * *}$ & $\mathrm{Y}>\mathrm{N}$ \\
\hline TDI & 55.45 & 1 & 55.45 & $6.33^{*}$ & $\mathrm{Y}>\mathrm{N}$ \\
\hline \multicolumn{6}{|c|}{ Presentation methods } \\
\hline Y & 1261.09 & 2 & 630.54 & $77 * * *$ & $\mathrm{~V}>\mathrm{TDI}>\mathrm{T} \& \mathrm{D}$ \\
\hline $\mathrm{N}$ & 723.28 & 2 & 361.64 & $32.79 * * *$ & $\mathrm{TDI}>\mathrm{V}>\mathrm{T} \& \mathrm{D}$ \\
\hline
\end{tabular}

Note. $\mathrm{Y}=$ with a concept map; $\mathrm{N}=$ without a concept map; $\mathrm{T} \& \mathrm{D}=$ text and diagram; $\mathrm{V}=$ video; $\mathrm{TDI}=$ text and diagram interaction.

$* * * P<.001, * P<.05$

Concerning the factor effects of concept maps, the results of the cognitive domain post-test differed significantly among the participants employing various presentation methods with $\mathrm{Y}$ or $\mathrm{N}$. As shown by posteriori comparisons, the cognitive domain post-test scores obtained by the participants with $\mathrm{Y}$ in the T\&D group were significantly $(P=.036)$ higher than those of the participants with $\mathrm{N}$. Moreover, the post-test results of the participants with $\mathrm{Y}$ in the $\mathrm{V}$ group $(M=86.33)$ were significantly $(P<.001)$ better than those of the participants with $\mathrm{N}(M=77.05)$. Similarly, the post-test results of the participants with $\mathrm{Y}$ in the TDI group $(M=83.12)$ were significantly $(P=.019)$ better than those of the participants with $\mathrm{N}(M=80.8)$.

Regarding the factor effects of presentation methods, the learning outcomes measured by the cognitive domain post-test differed significantly among the participants employing various presentation methods with $\mathrm{Y}$ or N. Posteriori comparisons indicate that, for the participants who received a concept map (Y), the beneficial effect of V $(M=86.88)$ on the cognitive domain post-test was significantly $(P=.033)$ better than that of TDI $(M=84.38)$. Likewise, the beneficial effect of TDI $(M=84.38)$ was significantly $(P<.001)$ better than that of T\&D $(M=73.75)$. For the participants who did not receive a concept map $(\mathrm{N})$, the beneficial effect of TDI $(M=80.54)$ on the cognitive domain post-test was significantly $(P=.004)$ better than that of $\mathrm{V}(M=76.42)$. Also, the beneficial effect of $\mathrm{V}(M=76.42)$ was significantly $(P=.001)$ better than that of T\&D $(M=70.04)$.

Effects of presentation methods and concept maps on the learning outcome of affection

As shown by the results of a within-group regression coefficient homogeneity test, neither the affective domain post-test $\times$ presentation methods $(F=.98, P=.33)$ nor the affective domain post-test $\times$ concept maps $(F=1.724, P=.19)$ reached a level of significance $(P>.05)$. Therefore, an ANCOVA could be directly conducted. Furthermore, the homogeneity of variances was examined through Levene's test of equality of error variances, with the results indicating that the variances of the groups were homogeneous $(P=.181>$ .05 ) and that an ANCOVA could be conducted. 
After the effect of the affective domain pre-test was eliminated, the two factors showed insignificant interactions $(F=1.28, P=.284>.05)$ in the affective domain post-test. However, the main effects of the two factors, i.e., presentation methods $(F=12.97, P<.001)$ and concept maps $(F=5.428, P=.023)$, achieved a level of significance. In other words, the treatment standards for presentation methods and concept maps had significantly different effects on the affective domain post-test. Accordingly, a test of simple main effects was implemented, with the results summarised in Table 8.

Table 8

The results of ANCOVA concerning the different effects of presentation methods and concept maps on the affective domain

\begin{tabular}{lrrrrr}
\hline Source & \multicolumn{1}{c}{ SS } & df & \multicolumn{1}{c}{ MS } & \multicolumn{1}{c}{ F } & Posteriori comparisons \\
\hline Concept maps & 54.25 & 1 & 54.25 & $5.43^{*}$ & Y > N \\
Presentation methods & 259.22 & 2 & 129.61 & $12.97 * * *$ & V > T\&D; V > TDI \\
Concept maps x & 25.62 & 2 & 12.81 & $1.28 \mathrm{n} . \mathrm{s}$. & \\
presentation methods & 709.65 & 71 & 9.99 & & \\
Error & 547479.00 & 78 & & & \\
\hline Total & & & \\
\hline
\end{tabular}

Note. $\mathrm{Y}=$ with a concept map; $\mathrm{N}=$ without a concept map; $\mathrm{T} \& \mathrm{D}=$ text and diagram; $\mathrm{V}=$ video; $\mathrm{TDI}=$ text and diagram interaction.

$* * * P<.001, * P<.05$, n.s. $P>.05$

Regarding the main effects of factors, the beneficial effects of the two factors on the affective domain post-test were analysed after the effect of the affective domain pre-test was eliminated. Posteriori comparisons show that, for the concept map factor, the beneficial effect of Y $(M=84.53)$ was significantly $(P=.023)$ better than that of $\mathrm{N}(M=82.83)$. For the presentation method factor, the beneficial effect of $\mathrm{V}(M=86.06)$ was significantly $(P<.001)$ better than that of T\&D $(M=81.62)$. Meanwhile, that of $\mathrm{V}(M=86.06)$ was significantly $(P=.003)$ better than that of TDI $(M=83.36)$. However, the difference in the beneficial effect between T\&D $(M=81.62)$ and TDI $(M=83.36)$ was insignificant.

Effects of presentation methods and concept maps on the learning outcome of psychomotor performance As shown by the results of a within-group regression coefficient homogeneity test, neither the psychomotor domain post-test $\times$ presentation methods $(F=2.42, P=.096)$ nor the psychomotor domain post-test $\times$ concept maps $(F=1.36, P=.247)$ reached a level of significance $(P>.05)$. In such a case, an ANCOVA could be directly conducted. Furthermore, the homogeneity of variances was examined through Levene's test of equality of error variances, with the results indicating that the variances of the groups were homogeneous $(P=$ $.181>.05$ ) and that an ANCOVA could be conducted.

After the effect of the psychomotor domain pre-test was eliminated, the two factors did not achieve a significant interaction $(F=.16, P=.85>.05)$ during the psychomotor domain post-test. Yet, the main effects of the two factors, that is, presentation methods $(F=55.62, P<.001)$ and concept maps $(F=5.17, P=.026)$, achieved a level of significance. These results indicate that various treatment standards for presentation methods and concept maps had significantly different effects on the psychomotor domain post-test. Therefore, a test of simple main effects was performed, with the results summarised in Table 9.

As for the main effects of the factors, the beneficial effects of the two factors on the psychomotor domain post-test were analysed after the effect of the psychomotor domain pre-test was eliminated. Posteriori comparisons show that, for the concept map factor, the beneficial effect of $Y(M=81.92)$ was significantly $(P$ $=.026)$ better than that of $\mathrm{N}(M=79.96)$. For the presentation method factor, the beneficial effect of $\mathrm{V}(M=$ 85.32) was significantly $(P=.015)$ better than that of TDI $(\mathrm{M}=82.71)$. Similarly, the beneficial effect of TDI $(\mathrm{M}=82.71)$ was significantly $(P<.001)$ better than that $\mathrm{T} \& \mathrm{D}(M=74.78)$. 
Table 9

The results of ANCOVA concerning the different effects of presentation methods and concept maps on the psychomotor domain

\begin{tabular}{lrrrrr}
\hline Source & \multicolumn{1}{c}{ SS } & \multicolumn{1}{c}{ df } & \multicolumn{1}{c}{ MS } & \multicolumn{1}{c}{ F } & Posteriori comparisons \\
\hline Concept maps & 72.80 & 1 & 72.80 & $5.17 *$ & Y $>$ N \\
Presentation methods & 1565.54 & 2 & 782.77 & $55.62 * * *$ & V > TDI $>$ T\&D \\
$\begin{array}{l}\text { Concept maps x } \\
\text { presentation methods }\end{array}$ & 4.44 & 2 & 2.22 & $.16 n . s$. & \\
Error & 999.21 & 71 & 14.07 & & \\
\hline Total & 514047 & 78 & & & \\
\hline
\end{tabular}

Note. $\mathrm{Y}=$ with a concept map; $\mathrm{N}=$ without a concept map; $\mathrm{T} \& \mathrm{D}=$ text and diagram; $\mathrm{V}=$ video; $\mathrm{TDI}=$ text and diagram interaction.

$* * * P<.001, * P<.05$, n.s. $P>.05$

\section{Effects of cognitive load on learning outcomes}

To examine the effects of cognitive load on learning outcomes of cognition, affection, and psychomotor performance, a simple regression analysis was performed to verify the relationships between cognitive load and learning outcomes. Additionally, cognitive load was treated as a predictor variable while the post-test scores of cognition, affection, and psychomotor performance were treated as criterion variables. The results are summarised in Table 10.

Table 10

The regression analysis results concerning the effects of cognitive load on learning outcomes

\begin{tabular}{lccc}
\hline & \multicolumn{3}{c}{ Dependent variable } \\
\cline { 2 - 4 } & $\begin{array}{c}\text { Cognitive domain } \\
\text { post-test }\end{array}$ & $\begin{array}{c}\text { Affective domain } \\
\text { post-test }\end{array}$ & $\begin{array}{c}\text { Psychomotor domain } \\
\text { post-test }\end{array}$ \\
\hline Independent variable & $\mathrm{R}^{2}=.716, \mathrm{DW}=.99$ & $\mathrm{R}^{2}=.258, \mathrm{DW}=1.9$ & $\mathrm{R}^{2}=.750, \mathrm{DW}=1.9$ \\
& $(F=191.24, P<.001)$ & $(F=26.39, P<.001)$ & $(F=228.37, P<.001)$ \\
Cognitive load & $\beta=-.846$ & $\beta=-.508$ & $\beta=-.866$ \\
& $(t=-13.83, P<.001)$ & $(t=-5.14, P<.001)$ & $(t=-15.11, P<.001)$ \\
\hline
\end{tabular}

${ }^{\text {a }}$ DW stands for Durbin-Watson.

As shown by the results above, all of the Durbin-Watson (DW) values were between 0.99 and 1.9, demonstrating that there were no self-correlations in the factors. As indicated by the regression analysis results in Table 11, cognitive load had significant effects on the test mode and the fitness of compatible information concerning the cognitive domain post-test, affective domain post-test, and psychomotor domain post-test $(\mathrm{R} 2=.716, \mathrm{~F}=191.24, P<.001 ; \mathrm{R} 2=.258, \mathrm{~F}=26.39, P<.001 ; \mathrm{R} 2=.750, \mathrm{~F}=228.37, P<.001$ respectively). The predictor variable (X), or cognitive load, had negative effects on the criterion variables (Y). In other words, the greater the reading-caused cognitive load was, the poorer the learning outcomes were in terms of the cognitive domain post-test, affective domain post-test, and psychomotor domain post-test ( $\beta=$ $.846, \mathrm{t}=-13.83, P<.001 ; \beta=-.508, \mathrm{t}=-5.14, P<.001 ; \beta=-.866, \mathrm{t}=-15.11, P<.001$ respectively). Finally, the above findings were integrated and a summary was compiled based on the research model, as shown in Figure 7. 


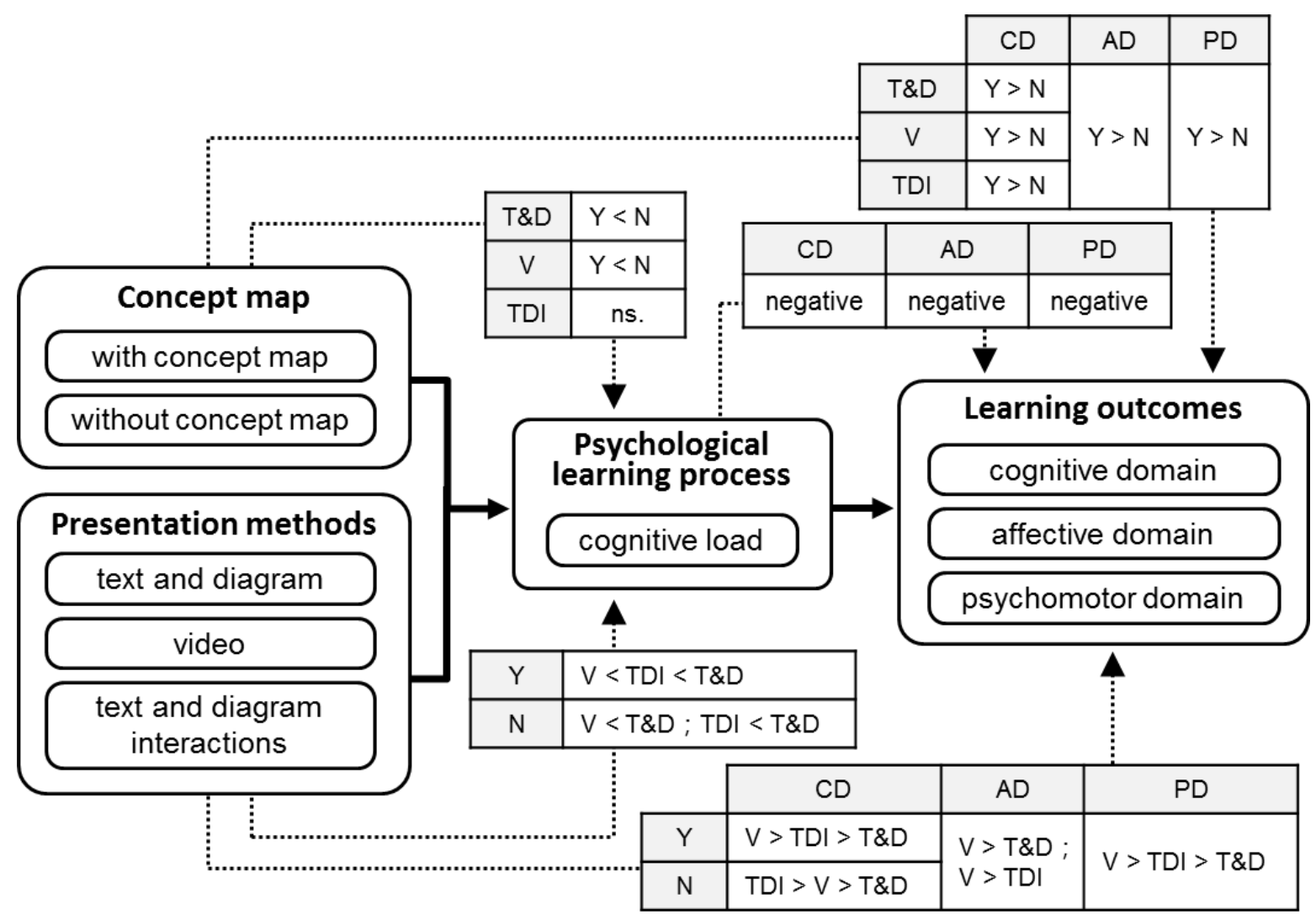

Figure 7. Summarised findings of the relevant variables based on the research model.

Note. $\mathrm{T} \& \mathrm{D}=$ text and diagram; $\mathrm{V}=$ video; $\mathrm{TDI}=$ text and diagram interaction; $\mathrm{Y}=$ with a concept map; $\mathrm{N}=$ without a concept map; $\mathrm{CD}=$ cognitive domain; $\mathrm{AD}=$ affective domain; $\mathrm{PD}=$ psychomotor domain. $\mathrm{ns} . p>.05$

\section{Discussion}

\section{Effects of presentation methods and concept maps on cognitive load}

From the findings above, it was discovered that when learners read e-textbooks by the TDI presentation method, the availability of concept maps produced no significant effect on their cognitive load. The reason for this phenomenon might lie in the design contents of TDI. Specifically, TDI enables learners to understand complex structures intuitively through interactive images and 3D objects. That is, TDI is somewhat capable of integrating concepts and relationships. It is inferred that TDI itself replaces some of the functions of a concept map; in consequence, having or not having a concept map has no significant effect on cognitive load.

In addition, the cognitive load imposed by various presentation methods on learners with a concept map (Y) ranked as follows: $\mathrm{V}<\mathrm{TDI}<\mathrm{T} \& \mathrm{D}$. By contrast, for learners with no concept map $(\mathrm{N})$, the cognitive load coming from various presentation methods ranked as follows: V $<$ T\&D and TDI $<$ T\&D. However, the difference between $\mathrm{V}$ and TDI was insignificant. In other words, the variations of cognitive load caused by $\mathrm{Y}$ and $\mathrm{N}$ in the $\mathrm{V}$ mode were significantly greater than those in the TDI mode. Although this phenomenon was a little unexpected, the authors believe that it could be analysed by the cognitive theory of multimedia learning as well as the manifest force of integrated concepts and relationships. 


\section{Effects of presentation methods and concept maps on the learning outcomes of cognition, affection, and psychomotor performance}

As for the combination treatments of the two factors, $V$ was inferior to TDI concerning the learning outcomes of the cognitive domain only when learners had no concept maps $(\mathrm{N})$. By contrast, $\mathrm{V}$ was superior to TDI in all the other situations. The authors suggest that a possible reason for this phenomenon is the design contents of TDI. Because of its characteristics, TDI not only replaces the function of a concept map to a certain degree but also provides a chance for intuitive understanding of complex structures in the cognitive domain.

Concerning the main effects of various presentation methods in the affective domain, the beneficial effects on learning outcomes ranked as follows: $\mathrm{V}>\mathrm{T} \& \mathrm{D}$ and $\mathrm{V}>\mathrm{TDI}$. However, the relationship between T\&D and TDI was insignificant. A possible reason for this phenomenon is that narration has a more substantial effect and spur on attitudes, interests, and values, thereby inducing the affective learning outcomes.

This study investigated the three constructs of learning outcomes; namely, cognition, affection, and psychomotor performance. As indicated by the findings, dual-sensed learning does not necessarily produce better learning outcomes than solely visual learning in the cognitive domain. Regarding the effects of concept maps on learning outcomes, it was found that when learners read e-textbooks with concept maps, their learning outcomes of cognition, affection, and psychomotor performance are better than when there are no concept maps. The result corresponds with what was presented in the above literature (refer to the Theoretical background section herein). Namely, through visualisation of individual concepts and relationships, concept maps can help learners organise knowledge (Hwang et al., 2011) and enhance learning outcomes (Hathorn \& Rawson, 2012; Novak \& Gowin, 1984).

\section{Effects of cognitive load on learning outcomes of cognition, affection, and psychomotor performance}

Cognitive load had significantly different effects on the learning outcomes of cognition, affection, and psychomotor performance; besides, their relationships were negatively correlated. This finding is consistent with those of previous studies (Lin \& Atkinson, 2011; Sweller \& Chandler, 1994). Therefore, the authors recommend reducing cognitive load to enhance the learning outcomes of cognition, affection, and psychomotor performance. As indicated by the findings herein, cognitive load displays some functions of a mediator, so it can account for some effects exerted by dependent variables on independent variables. This corresponds with the conceptual framework of TML presented by Alavi and Leidner (2001).

But how can cognitive load be reduced? This study suggests that concept maps can be provided as advance organisers of the layout of e-textbooks. Besides visualising the concepts of knowledge topics to reduce cognitive load, concept maps enable learners to organise and integrate new knowledge, thereby increasing their learning outcomes of cognition, affection, and psychomotor performance. Furthermore, as for the presentation method for learning materials, the $\mathrm{V}$ method with a concept map $(\mathrm{Y})$ can minimise cognitive load. Alternatively, the V or TDI method can be employed when concept maps are absent.

\section{Research implications}

Adopting a tablet as an e-reader, this study analysed how instructional design of e-textbooks supported by several new kinds of hardware, such as a multi-touch screen, can shape learning material to enhance learners' learning outcomes. Almost all past studies suggested that dual senses have a better effect on learning outcomes than a single sense. This study divided learning outcomes into three domains and examined them. As indicated by the findings, in terms of the cognitive domain, dual senses do not necessarily have a better effect on learning outcomes than a single sense. Finally, as shown by the study results, concept maps in the three presentation methods, (i.e., T\&D, V, and TDI), play different roles in cognitive load and learning outcomes. The above findings can serve as the basis for subsequent researches on relevant topics. 
From the standpoint of practicality, this study may serve as a reference for teachers and instructional designers who engage in instructional design of e-textbooks. Based on the results compiled in Figure 7, e-instructional designers can select a combination of one presentation method and a concept map, which will generate the minimum cognitive load. Alternatively, they can select a combination that produces better learning outcomes, according to different emphases on cognition, affection, or psychomotor performance. For example, in accordance with the findings of this study, the following measures are recommended to achieve excellent learning outcomes:

- Regarding layout, a concept map can be provided as an advance organiser.

- Regarding presentation methods, the V method should be used.

- When a concept map is not available and the learning contents in the cognitive domain are emphasised, the TDI method should be used.

The results of this study apply not only to tablets but also to PCs with multi-touch screens and interactive whiteboards used in classrooms.

Because of the increased popularity of tablets, the era of e-textbooks has been approaching faster. In response to current developmental requirements for e-textbook applications, the authors investigated the presentation methods and concept maps used in instructional design of learning materials, with the following findings:

1. Overall, $\mathrm{V}$ is superior to TDI, and TDI is superior to T\&D regardless of cognitive load or learning outcomes.

2. Concept maps not only reduce learners' cognitive load, but increase their learning outcomes in three different domains, that is, cognition, affection, and psychomotor performance.

3. In the psychological learning processes, cognitive load proves to be a partial mediator. Therefore, in addition to IT and instructional strategy, methods which enhance learners' psychological learning processes must be emphasised in order to generate better learning outcomes.

This study took an initial step towards investigating the novel e-textbook reader, focusing on not only presentation methods but also on concept maps, which are classified under the category of layout. Although other related issues or the variables that can influence psychological learning processes were not addressed, the topics investigated in this study significantly influence learning. Therefore, it is anticipated that subsequent scholars can explore the application and development of e-textbooks in the field of education, contemplating as well as innovating their potential uses.

\section{References}

Alavi, M., \& Leidner, D. E. (2001). Research commentary: Technology-mediated learning - A call for greater depth and breadth of research. Information Systems Research, 12(1), 1-10.

Anderson, L. W., Krathwohl, D. R., Airasian, P. W., Cruikshank, K. A., \& Mayer, R. E. (2001). Summary of the changes from the original framework. In L. W. Anderson, D. R. Krathwohl, \& B. S. Bloom (Eds.), A taxonomy for learning, teaching, and assessing: A revision of Bloom's taxonomy of educational objectives (pp. 263-270). New York : Longman.

Berlanga, A. J., van Rosmalen, P., Boshuizen, H. P. A., \& Sloep, P. B. (2012). Exploring formative feedback on textual assignments with the help of automatically created visual representations. Journal of Computer Assisted Learning, 28(2), 146-160. doi:10.1111/j.1365-2729.2011.00425.x

Bloom, B. S. (1984). Taxonomy of educational objectives, Handbook 1: Cognitive domain (2nd ed.). $<$ Boston $>$ : Addison Wesley.

Bobrowski, P. (n.d.). Bloom's taxonomy: Expanding its meaning. Retrieved from http://www.pcrest3.com/fgb/efgb4/2/2_2_1.htm

Cerpa, N., Chandler, P., \& Sweller, J. (1996). Some conditions under which integrated computer-based training software can facilitate learning. Journal of Educational Computing Research, 15(4), 345-367. 
Chang, K.-E., Sung, Y.-T., \& Chiou, S.-K. (2002). Use of hierarchical hyper concept map in web-based courses. Journal of Educational Computing Research, 27(4), 335-353.

Elorriaga, J. A., Arruarte, A., Calvo, I., Larrañaga, M., Rueda, U., \& Herrán, E. (2011). Collaborative concept mapping activities in a classroom scenario. Behaviour \& Information Technology, 32, 1-13. doi:10.1080/0144929X.2011.632649

Gronlund, N. E. (1993). How to make achievement tests and assessments (5th ed.). Boston : Allyn \& Bacon.

Hathorn, L. G., \& Rawson, K. A. (2012). The roles of embedded monitoring requests and questions in improving mental models of computer-based scientific text. Computers \& Education, 59(3), 1021-1031. doi:10.1016/j.compedu.2012.04.014

Hede, A. (2002). Integrated model of multimedia effects on learning. Journal of Educational Multimedia and Hypermedia, 11(2), 177-191.

Hwang, G.-J., Wu, P.-H., \& Ke, H.-R. (2011). An interactive concept map approach to supporting mobile learning activities for natural science courses. Computers \& Education, 57(4), 2272-2280. doi:10.1016/j.compedu.2011.06.011

Issa, N., Schuller, M., Santacaterina, S., Shapiro, M., Wang, E., Mayer, R. E., \& DaRosa, D. A. (2011). Applying multimedia design principles enhances learning in medical education. Medical Education, 45(8), 818-826. doi:10.1111/j.1365-2923.2011.03988.x

Jonassen, D. H. (1997). Instructional design models for well-structured and iII-structured problem-solving learning outcomes. Educational Technology Research and Development, 45(1), 65-94.

Kalyuga, S. (2000). When using sound with a text or picture is not beneficial for learning. Australasian Journal of Educational Technology, 16, 161-172. Retrieved from http://ascilite.org.au/ajet/submission/index.php/AJET/index

Kao, G. Y.-M., Lin, S. S. J., \& Sun, C.-T. (2008). Breaking concept boundaries to enhance creative potential: Using integrated concept maps for conceptual self-awareness. Computers \& Education, 51(4), 1718-1728. doi:10.1016/j.compedu.2008.05.003

Kearney, P. (2004). Affective learning. In R. B. Rubin, P. Palmgreen, \& H. E. Sypher (Eds.), Communication research measures: A sourcebook (pp. 238-241). New York: Guilford Press.

Koc, M. (2012). Pedagogical knowledge representation through concept mapping as a study and collaboration tool in teacher education. Australasian Journal of Educational Technology, 28, 656-670. Retrieved from http://ascilite.org.au/ajet/submission/index.php/AJET/index

Lai, F.-Q., \& Newby, T. J. (2012). Impact of static graphics, animated graphics and mental imagery on a complex learning task. Australasian Journal of Educational Technology, 28, 91-94. Retrieved from http://ascilite.org.au/ajet/submission/index.php/AJET/index

Lee, K.-C. (2009). Taxonomy of educational objectives in cognitive, affective, and psychomotor domains: Applications in assessment. Taipei: Higher Education Publishing Co.

Lin, L., \& Atkinson, R. K. (2011). Using animations and visual cueing to support learning of scientific concepts and processes. Computers \& Education, 56(3), 650-658. doi:10.1016/j.compedu.2010.10.007

Linn, R. L., \& Miller, M. D. (2005). Measurement and assessment in teaching. London : Prentice Hall.

Mayer, R. E. (2001). Multimedia learning. Cambridge, UK Cambridge University Press.

Mayer, R. E. (2005). The Cambridge handbook of multimedia learning. New York: Cambridge University Press

Mayer, R. E. (2008). Applying the science of learning: Evidence-based principles for the design of multimedia instruction. American Psychologist, 63(8), 760.

Mayer, R. E. (2011). Applying the science of learning to multimedia instruction. In J. Mestre \& B. H. Ross (Eds.), Cognition in education (pp. 77-103). San Diego, Calif. : Elsevier Science.

Mayer, R. E., Heiser, J., \& Lonn, S. (2001). Cognitive constraints on multimedia learning: When presenting more material results in less understanding. Journal of Educational Psychology, 93(1), 187.

Mehrens, W. A., \& Lehmann, I. J. (1991). Measurement and evaluation in education and psychology (4th ed.). New York : Holt, Rinehart and Winston.

Novak, J. D., \& Gowin, D. B. (1984). Learning how to learn. New York, NY: Cambridge University Press.

Paas, F. G. W. C., \& van Merriënboer, J. J. G. (1994). Variability of worked examples and transfer of geometrical problem-solving skills: A cognitive-load approach. Journal of Educational Psychology, 86(1), 122-133. 
Pastore, R. (2012). The effects of time-compressed instruction and redundancy on learning and learners' perceptions of cognitive load. Computers \& Education, 58(1), 641-651. doi:10.1016/j.compedu.2011.09.018

Ruiz, J. G., Cook, D. A., \& Levinson, A. J. (2009). Computer animations in medical education: A critical literature review. Medical Education, 43(9), 838-846. doi:10.1111/j.1365-2923.2009.03429.x

Shah, A. (2012, January 20). Apple tries to redefine textbooks with iBooks 2. TechLife. Retrieved from http://www.techcentral.ie/18146/apple-tries-to-redefine-textbooks-with-ibooks-2

Sharda, R., Romano, N. C., Lucca, J., Weiser, M., Scheets, G., Chung, J.-M., \& Sleezer, C. M. (2004). Foundation for the study of computer-supported collaborative learning requiring immersive presence. Journal of Management Information Systems, 20(4), 31-64.

Simpson, E. J. (1972). The classification of educational objectives in the psychomotor domain. Washington, DC: Gryphon House.

Smith, S. M., \& Woody, P. C. (2000). Interactive effect of multimedia instruction and learning styles. Teaching of Psychology, 27(3), 220-223.

Sweller, J. (1990). On the limited evidence for the strategies. Journal for Research in Mathematice Education, 21(5), 411-415.

Sweller, J., \& Chandler, P. (1994). Why some material is difficult to learn. Cognition and Instruction, 12(3), 185-233.

Sweller, J., van Merriënboer, J., \& Paas, F. (1998). Cognitive architecture and instructional design. Educational Psychology Review, 10(3), 251-296. doi:10.1023/a:1022193728205

van Merriënboer, J. J. G., \& Sweller, J. (2010). Cognitive load theory in health professional education: Design principles and strategies. Medical Education, 44(1), 85-93.

Wilson, E. O., Ryan, M., \& McGill, G. (2012). E.O. Wilson's life on Earth: An introduction. Durham, NC: E. O. Wilson Biodiversity Foundation.

Wierwille, W. W., \& Eggemeier, F. T. (1993). Recommendations for mental workload measurement in a test and evaluation environment. Human Factors: The Journal of the Human Factors and Ergonomics Society, 35(2), 263-281. doi:10.1177/001872089303500205

Young, J. R. (2012, January 22). Campus reactions to Apple's entry into e-textbook market. Wired Campus. Retrieved from

http://chronicle.com/blogs/wiredcampus/campus-reactions-to-apples-entry-into-e-textbook-market/35119

Corresponding author: Kuo-Liang Huang, shashiliang@gmail.com

Australasian Journal of Educational Technology (C) 2014.

Please cite as: Huang, K-L., Chen, K-H., Ho, C-H. (2014). Enhancing learning outcomes through new e-textbooks: A desirable combination of presentation methods and concept maps. Australasian Journal of Educational Technology, 30(5), 600-618. 